7. Reprod. Fert. (1969) 20, 129-131

\title{
APPLICATION OF EOSIN FOR DIFFERENTIAL STAINING OF BUFFALO SPERMATOZOA
}

\author{
IV. USE OF OPAL BLUE-EOSIN
}

\author{
A. ALY NOUR EL-DIN*, M. A. OMAR, A. A. YOUNES AND \\ M. Y. ABBOUD \\ National Research Centre, Cairo, U.A.R.
}

(Received 11th February 1969)

Buffalo semen has received relatively little attention owing to the fact that buffaloes are mainly found in recently developing countries, where artificial insemination is not widely applied. The methods routinely followed in artificial insemination may require to be modified so as to suit the nature and peculiarities of this species.

In the process of semen evaluation, the motility test has a special importance, as fertilization is expected only when there is a certain percentage of active, progressively motile spermatozoa. Differential staining can be used for estimating the percentage of live spermatozoa. Staining with opal blue-eosin mixture has been applied to a certain extent in semen evaluation. Lasley \& Bogart (1943) employed this mixture for beef cattle and reported a correlation of +0.41 between the percentage of live spermatozoa and motility, and +0.83 between fertility and the percentage of live spermatozoa. Emik \& Sidwell (1947) stained ram semen with a solution containing $12.5 \%$ opal blue and $0.5 \%$ eosin. However, Schmidt \& Jenichen (1952) reported that opal blue-eosin was unsuitable for semen evaluation, particularly in the case of fresh ejaculates. Rao (1957a) stained undiluted buffalo semen for the study of sperm morphology and found that, among the stains giving a blue background, $7 \%$ methyl blue and $1: 2$ to $1: 4$ dilution of the stock opal blue solution gave the best results. Congo red $(2 \%)$ was also very good. Rao (1957b) reported that the stock opal blue solution diluted 1:5 is one of the best blue counterstains. Nour El-Din, Omar, Younes \& Abboud (1968) and Nour El-Din, Younes, Abboud \& Omar (1968) found that, for buffalo semen, yellowish eosin was more efficient than bluish eosin and the optimum concentration of the stain was 1.6 to $1.7 \%$. The present work was carried out to determine the efficiency of opal blue at two levels $(12.50 \%$ and $6.25 \%$, each combined with $1.70 \%$ yellowish eosin, in the process of buffalo semen evaluation. The suitability of opal blue-eosin in comparison with other stain mixtures containing nigrosin, methyl blue and congo red as backgrounds was also determined. Weighed amounts of opal blue and eosin were dissolved in normal saline solution. Mixtures composed of $10 \%$ nigrosin, $7 \%$ methyl blue and $2 \%$ congo red, each combined with $1.70 \%$ yellowish eosin, were also prepared. The study included fifteen ejaculates from three buffalo bulls. Motility ratings were made initially on undiluted buffalo

\footnotetext{
* Present address: Laboratory of Physiology and Genetics of Animals, Liběchov, Czechoslovakia.
} 
semen according to the method of Milovanov (1962). Fresh undiluted buffalo semen was used for differential staining. Staining was performed with the five stain mixtures on five smears from each ejaculate, the smears being spread over the whole slide and fixed by air drying. Four fields of view, chosen at random and representing the whole area of the slide were microscopically investigated. The numbers of unstained (live) and stained (dead) spermatozoa were counted in each field.

The mean percentage of motility was $63 \cdot 00 \pm 1 \cdot 57$. The results of differential staining with each stain mixture are given in Table 1. The background was

TABLE 1

DIFFERENTIAL STAINING OF BUFFALO SEMEN WITH DIFFERENT STAIN MIXTURES

\begin{tabular}{l|c|c|c|c}
\hline \multicolumn{1}{c|}{ Stain mixture used } & $\begin{array}{c}\text { No. of } \\
\text { unstained sperm. }\end{array}$ & $\begin{array}{c}\text { No. of } \\
\text { stained sperm. }\end{array}$ & $\begin{array}{c}\text { Total count } \\
\text { of sperm. }\end{array}$ & $\begin{array}{c}\% \text { live } \\
\text { sperm. }\end{array}$ \\
\hline $12 \cdot 50 \%$ opal blue-cosin & 2462 & 4608 & 7070 & $34 \cdot 82 \pm 0 \cdot 57$ \\
$6 \cdot 25 \%$ opal blue-eosin & 4701 & 2479 & 7180 & $65 \cdot 47 \pm 0 \cdot 56$ \\
Eosin-nigrosin & 4465 & 2580 & 7045 & $63 \cdot 38 \pm 0 \cdot 57$ \\
Methyl blue-eosin & 3924 & 3216 & 7140 & $54 \cdot 96 \pm 0 \cdot 59$ \\
Congo red-eosin & 3765 & 3305 & 7070 & $53 \cdot 26 \pm 0 \cdot 59$ \\
Total & 19317 & 16188 & 35505 & $54 \cdot 41 \pm 0 \cdot 26$ \\
\hline
\end{tabular}

bluish with opal blue and methyl blue mixtures, and reddish with congo red. Nigrosin imparted a dark blackish background, which was better, as it provided a stronger contrast between the background and the spermatozoa. However, Rao (1957a) considered that stains with a blue or bluish violet background were better than nigrosin.

The present results revealed that $6.25 \%$ opal blue-eosin mixture was more suitable than $12.50 \%$ opal blue-eosin, as it led to a higher percentage of live spermatozoa, corresponding better with the observed motility, and, as reported by Lasley \& Bogart (1943), showing a high positive correlation with it $(r=$ +0.903 ). Use of $12.50 \%$ opal blue-eosin led to an insignificant positive correlation $(r=+0.194)$ with motility. Moreover, by applying the lower concentration of the stain, the differential count was easier and the cytoplasmic droplets were more distinct, appearing as white, unstained areas or as pale blue masses. With the higher concentration, the droplets were very dark and sometimes obscure. This indicates that stain concentration can influence the results of differential staining in buffalo semen. The percentage of live spermatozoa obtained by using $6.25 \%$ opal blue-eosin was somewhat higher $(2 \cdot 47)$ than the observed percentage of motile spermatozoa. This may be attributed to the fact that some spermatozoa were still alive at the moment of staining, but were not motile. The cellular membranes of these spermatozoa presumably kept their impermeability to stains and accordingly were counted as alive.

Our conclusion concerning the value of the opal blue-eosin mixture is not in agreement with Schmidt \& Jenichen (1952), who maintained that this mixture was unsuitable for semen evaluation.

For the differentiation of spermatozoa, eosin-nigrosin was found to be more suitable, as it led to a better staining reaction and a percentage of live sperma- 
tozoa that coincided more closely with motility, but for the better clarification of cytoplasmic droplets, opal blue-eosin can be used. The other stain mixtures cannot be recommended in the practice of artificial insemination in buffaloes, as they lead to significant variations between estimated percentages of live and motile spermatozoa.

\section{REFERENCES}

Емік, L. O. \& Sidwell, G. M. (1947) Refining methods for using opal blue stain in evaluating ram semen. 7. Anim. Sci. 6, 67.

LASLEy, J. F. \& Bogart, R. (1943) Some factors influencing reproductive efficiency of range cattle under artificial and natural breeding conditions. Bull. Miss. agric. Exp. Stn, 376.

Milovanov, V. K. (1962) Biology of reproduction and artificial insemination in animals, Part I, p. 438. Izdat. Sel.-khoz. Lit., Moscow.

Nour El-Din, A. Aly, Omar, M. A., Younes, A. A. \& Abboud, M. Y. (1968) I. Efficiency of fluorescein derivatives for differential staining. VIth Int. Cong. Anim. Reprod. Artif. Insem., Paris. Résumés, p. 195. Institut de la Recherche Agronomique, France.

Nour El-Din, A. Aly, Younes, A. A., Abboud, M. Y. \& Omar, M. A. (1968) II. Stain concentration and sperm differentiation in buffaloes. VIth Int. Cong. Anim. Reprod. Artif. Insem., Paris. Résumés, p. 196. Institut de la Recherche Agronomique, France.

RAo, C. K. (1957a) Negative staining for the study of sperm morphology. Vet. Rec. 69, 1084.

RAo, C. K. (1957b) Differential staining of spermatozoa. Br. vet. F. 113, 323.

Schmid, K. \& Jenichen, W. (1952) Versuche mit Bullensperma zur Differenzierung toter und lebender Spermien mit der Eosin-Opal blau-Farbung. M.h. VetMed. 7, 357. 